\title{
DO CITIZENS OF A CITY THAT OWNS A LOCAL PUBLIC AIRPORT HAVE \\ ATTACHMENT TO THE AIRPORT AND USE IT?
}

Yu Morimoto

Konan University, Japan

Takeshi Koide

Konan University, Japan

Yuko Sugiura

Konan University, Japan

\section{ABSTRACT}

This research investigates whether passengers living in a city with a local public airport have an attachment to that airport and tend to use it. Focusing on the greater Kansai area with its three airports and Kobe, which owns one of them, Kobe Airport, as an example, an empirical analysis was conducted using a nested logit model and micro data. The result of the basic model shows that passengers living in Kobe prefer the Kobe Airport when compared to passengers living in other cities in the Greater Kansai Area. An additional analysis based on a questionnaire survey revealed that a certain percentage of respondents choose Kobe Airport just because they prefer it, meaning that the non-economic factor of attachment influences passengers' decisions. The results of this research suggest that enhancing attachment to an airport might be a possible idea for policy makers of airport cities to increase their passengers.

\section{KEYWORDS}

Airport choice, Multiple airport region, Airport city, Attachment, Nested logit model, Revealed preference data 


\section{INTRODUCTION}

Airports are essential transport infrastructures for long-distance travel, and they contribute to the regional economy of airport cities by making the interactions among cities more convenient. Therefore, with strong requests and support from citizens and industries, some local governments have constructed and own their airports. The construction costs of these local public airports are mainly paid for by taxpayers, and if the airports run a deficit, the local government is required to make up the deficit with taxes. Nevertheless, the use of taxes can be justified if citizens need and use the airports. In addition, if more citizens use the airport, the deficit will be reduced, and the airport will even be profitable, which is positive for the local government's finances. Therefore, it should be of great interest for policy makers of airport cities to determine whether citizens are willing to use their local airports and how to increase their use.

There are mainly two situations in which citizens of airport cities make decisions whether they use their local airport. The first is the choice of transportation mode. For mediumdistance travel, passengers can choose among flying, railways, buses, cars and so on. In countries with high-speed railways, there is fierce competition between airlines and railway companies for inter-city traffic of $500 \mathrm{~km}$ to $1,000 \mathrm{~km}$. In fact, in Japan, passengers can choose between flights and the Shinkansen to travel between Tokyo and Hiroshima and Tokyo and Yamaguchi, and the market shares of air transport and railways on these routes are very close ${ }^{1}$. The second situation is airport choice among multiple airports in the same region. For example, London (Heathrow, Gatwick, Stansted etc.), New York (JFK, LaGuardia, Newark) and the Pearl River Delta (Hong Kong, Shenzen, Guangzhou) are well known as multi-airport regions. In a multi-airport region, passengers can choose the most desirable airport to maximise their utility. This study focuses on the latter situation-that is, a multi-airport region-in order to clarify whether citizens of a city with a local public airport prefer that airport over other airports.

In addition, a psychological factor is focused on to explain the background of the decisions made by citizens of airport cities. Previous research on transportation economics has explained decisions from the viewpoint of economic factors such as fares

\footnotetext{
1 The distance between Tokyo and Hiroshima is $674 \mathrm{~km}$, and the market share of air transport and railway transport is $33.8 \%$ and $64.3 \%$, respectively. The distance between Tokyo and Yamaguchi is $768 \mathrm{~km}$, and the market share of air transport and railway transport is 65.5\% and 32.6\%, respectively. Data source: 2015 Inter-Regional Travel Survey by Ministry of Land, Infrastructure, Transportation and Tourism.
} 
and access costs, and that of convenience such as the number of flights and airport facilities (Hess et al. (2007) and Marcucci and Gatta (2011)). However, previous studies in marketing have indicated that product loyalty influences purchasing behaviour (Halpern and Graham (2013)). In the choice of airport, if citizens are attached to their local airport, they may be motivated to use it. Since public opinion is one of important factors in the construction of local public airports that requires huge financial resources, it is quite possible that citizens who requested or supported the construction of the airport feel a sense of attachment and have loyalty to it.

Here, the research questions can be summarised as the following:

i) Do citizens of a city that owns a local public airport tend to use it?

ii) Does the psychological factor of attachment influence airport choice behaviour?

\section{LITERATURE REVIEW}

Following Harvey (1987), who formulated passengers' behaviour based on the discrete choice model, much research on airport choice has focused on passengers' decisions and the factors that influence them. Most of the early studies measured the effects of access time and access cost to the airport, flight frequency and fares (e.g., Innes and Doucet 1990; Windle and Dresner 1995). Recent research has made more use of the nested logit (NL) model to investigate combined choices while considering multiple factors. Pels et al. (2000) and Jung and Yoo (2016) analysed passengers' decisions regarding a combination of airports and airlines. Zhou et al. (2019) analysed the choice of transportation mode and airline. Although much research on airport choice has been conducted, only few papers have focused on passengers in a specific region or city. Lian and Ronnevik (2011) and Morimoto (2019) focused on the choices of passengers living in an airport city and showed that those passengers preferred larger and further airports to their smaller and closer local airports because flight frequency is higher at the larger airports. However, these papers did not analyse differences in preference between citizens of an airport city and other passengers.

In general, customer loyalty is an important factor in marketing. Jones et al. (2002) found that the source of loyalty is switching costs and that the strength of a customer's connection to a particular product creates consistency in product selection. As for the airline industry, Basso et al. (2009) and de Boer and Gudmundsson (2012) indicated that airlines have strategically introduced frequent flyer programmes in order to increase 
passengers' cost of switching over to competitors. This is an example where airlines use economic incentives to strengthen their connection with customers. Although attachment is not an economic factor, psychological connection with a product makes customers less willing to switch to another product. An example of how attachment to a region or home country is reflected in purchasing behaviour is seen in the 'buy local' phenomenon, where people buy local products to support local businesses (Saffu et al. 2010; McEntee 2010). As another example, in terms of equity investment, Seasholes and Zhu (2013) showed that individual investors tend to invest in the shares of companies that are geographically close to them. In this way, people are connected to their local companies and products to some extent. Thus, it could be hypothesised that people tend to choose their city's airport just because it is in their city. Nesset and Helgesen (2014), Castro and Lohmann (2014) and Bezerra and Gomes (2019) studied airport loyalty from the viewpoint of airport branding and the importance of airport facilities. However, so far, there is no research related to the hypothesis.

The originality of this research is its focus on regionality and the psychological factor in passengers' airport choice. In this paper, regionality means that people have a specific preference for something located in their place of residence. In the context of air transportation, regionality indicates preference of citizens of airport cities to the local airport and will be defined in the empirical model in Section 4 as the dummy variables. While previous studies have investigated the general effects of various factors such as airport access, ticket price and airport facilities on passengers' decisions, this research analyses the preference of citizens of airport cities. That is, this research attempts to answer the question of whether passengers who live in an airport city behave differently from those in other cities because of an attachment to their local airport. For this purpose, the behaviours of passengers in the Greater Kansai Area (GKA) of Japan are analysed. In GKA, there are three airports: Kansai International Airport (KIX), Itami Airport (ITM) and Kobe Airport (UKB). Only UKB is a local public airport owned by Kobe. Using micro data, this research examines whether citizens of Kobe are likely to choose UKB when compared to other passengers. The details of GKA and the three airports are introduced in the next section.

The structure of this study is as follows. Section 3 introduces GKA and the three airports. It describes the history of UKB and the reason the area is a suitable subject for the study of passengers' regionality. In section 4, the research method and data used in this study 
are explained. Although the analysis in this study is based on the standard nested logit (NL) model, a new variable is added to capture the preference of Kobe citizens. Section 5 discusses the results of the analysis. Some additional questions are examined. The first is whether only the citizens of Kobe prefer their local airport or if passengers who live near other airports also prefer their local airports. The second is whether passengers living in cities around Kobe also behave similarly to Kobe citizens. In section 6 , the relationship between airport choice and attachment is investigated based on the questionnaire survey. Section 7 contains concluding remarks.

\section{The GREATER KANSAI AREA AND THE THREE AIRPORTS}

In this section, Greater Kansai Area (GKA) and its three airports are described. In Figure 1, GKA is indicated by the greyed-out area and is defined as the $1.5 \%$ urban employment area centred in Osaka. It is the second largest metropolitan area in Japan, with a total population of approximately 20 million. GKA includes Kyoto, the historical tourist city, and Kobe, the international port city. There are three airports in GKA, i.e., Kansai International Airport (KIX), Itami Airport (ITM) and Kobe Airport (UKB). The airports are located close to each other, and the distance between the airports is only $20-40 \mathrm{~km}$. Thus, GKA can be considered a multi-airport region, and passengers can choose which airport to use. Table 1 summarises the basic information about each airport. Only KIX is an international airport, and it serves as an international gateway to GKA. Although ITM is easily accessible from major cities, international flights are prohibited, and only domestic flights are allowed. However, ITM is the main domestic airport, whose share of domestic passengers among the three airports is $63 \%$ due to its convenient access. UKB is a small airport with one runway, and it serves only domestic flights.

The reason for the co-existence of the three airports is as follows. In the past, ITM was the only airport in GKA, but due to the rapid increase in demand for air travel caused by rapid economic growth, it was not possible to provide enough slots for flights, and congestion became a problem. Since ITM was located in urbanised area, there was no room for expansion, and the noise problem worsened, so in the 1970s, the Japanese government took the initiative to construct a new airport to serve as a gateway to GKA. At first, Kobe was chosen as the location for the new airport, but the city refused to accept it because airports were regarded as nuisance facilities at the time. As a result, the Senshu area in the southern Osaka prefecture was selected as the final construction site, and KIX opened in 1994. After this, Kobe changed its mind about the need for the 
airport to develop the local economy and provide convenience for the citizens of Kobe. However, it was no longer possible to construct the third airport in GKA as a national project, so Kobe had to construct it by itself. The construction of the airport has been a point of contention in many mayor elections because it required significant payment from taxes and the issuance of municipal bonds. In the 1997 and 2001 elections, a pro-airport mayor was elected. Finally, UKB was opened in 2006 with the support of citizens as well as local politicians.

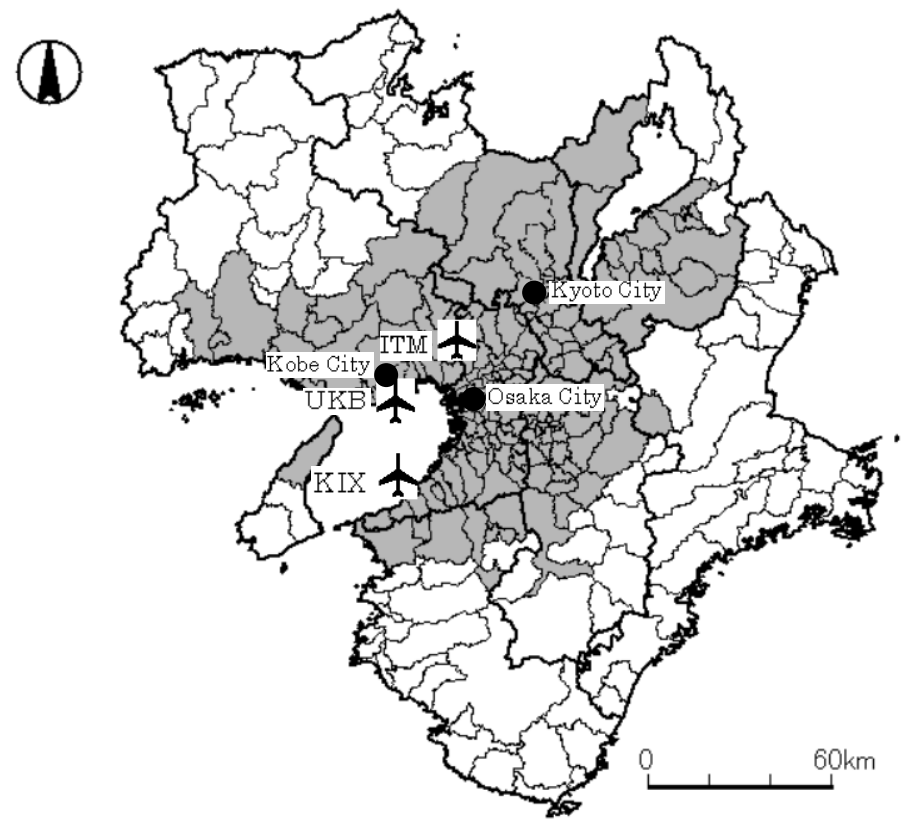

Figure 1. The greater Kansai area and the three airports

Table 1. Basic data of the three airports

\begin{tabular}{|c|c|c|c|c|}
\hline & & KIX & ITM & UKB \\
\hline Open & (year) & 1994 & 1939 & 2006 \\
\hline Owne & rship & $\begin{array}{l}\text { Company owned by } \\
\text { national government }\end{array}$ & National government & Kobe city \\
\hline Oper & ation & $\begin{array}{l}\text { The three } \\
\text { by the private }\end{array}$ & $\begin{array}{l}\text { airports are integrally } \\
\text { company, Kansai airpo }\end{array}$ & $\begin{array}{l}\text { ted } \\
2018\end{array}$ \\
\hline Runw & $v \in(m)$ & 4000 & 3000 & 2500 \\
\hline runivo & ys (iii) & 3500 & 1828 & \\
\hline Passengers & International & 22,439 & & \\
\hline (2018, Thousands) & Domestic & 6,513 & 16,184 & 3,182 \\
\hline Direct routes & International & 75 & . & \\
\hline (Summer, 2019) & Domestic & 17 & 26 & 7 \\
\hline Access time to major & Osaka city & 45 & 22 & 48 \\
\hline cities by train & Kyoto city & 108 & 63 & 79 \\
\hline (minutes) & Kobe city & 98 & 46 & 18 \\
\hline
\end{tabular}

The three airports operated separately until 2018 (KIX was managed by a national government-owned company; ITM was owned by the national government; and UKB 
was owned by Kobe), which made it difficult to achieve total optimisation. Thus, the three airports were privatised under the concession system, and their operation was integrated into one private concessionaire company, Kansai Airport Co., Ltd., in 2018. Although UKB was privatised, Kobe maintains the ownership of UKB, and the contract with Kansai Airport includes a clause dictating that Kobe receive a revenue-linked concession fee ${ }^{2}$. Thus, UKB is still the property of Kobe, and it is still important for Kobe to increase its passengers because a certain portion of the revenue is returned to the city.

Next is the outline of the air transport market in GKA. In 2015, the three airports served flights to six cities in common: Sapporo, Sendai, Tokyo, Nagasaki, Kagoshima and Naha. When travelling to or from these cities, passengers can choose an airport to use from among the three airports. Figure 2-4 show an overview of airport choice behaviours. Figure 2 shows the selection rate of UKB for each origin/destination point. $40-60 \%$ of passengers whose origin/destination was Kobe selected UKB, which indicates that UKB has the largest share of flight demand in Kobe. However, it is clear from Figures 3 and 4, which show the selection rates for ITM and KIX, that passengers tend to choose the airport closest to their origin or destination because of easy access. Therefore, to conclude whether Kobe citizens prefer their airport, it is necessary to control for factors that can influence passengers' airport choice decisions, such as access time and cost to each airport. For this purpose, the NL model is used in this paper.

2 If operating revenues exceed 2 billion yen in a year, Kobe receives $3 \%$ of the exceeded revenue. 


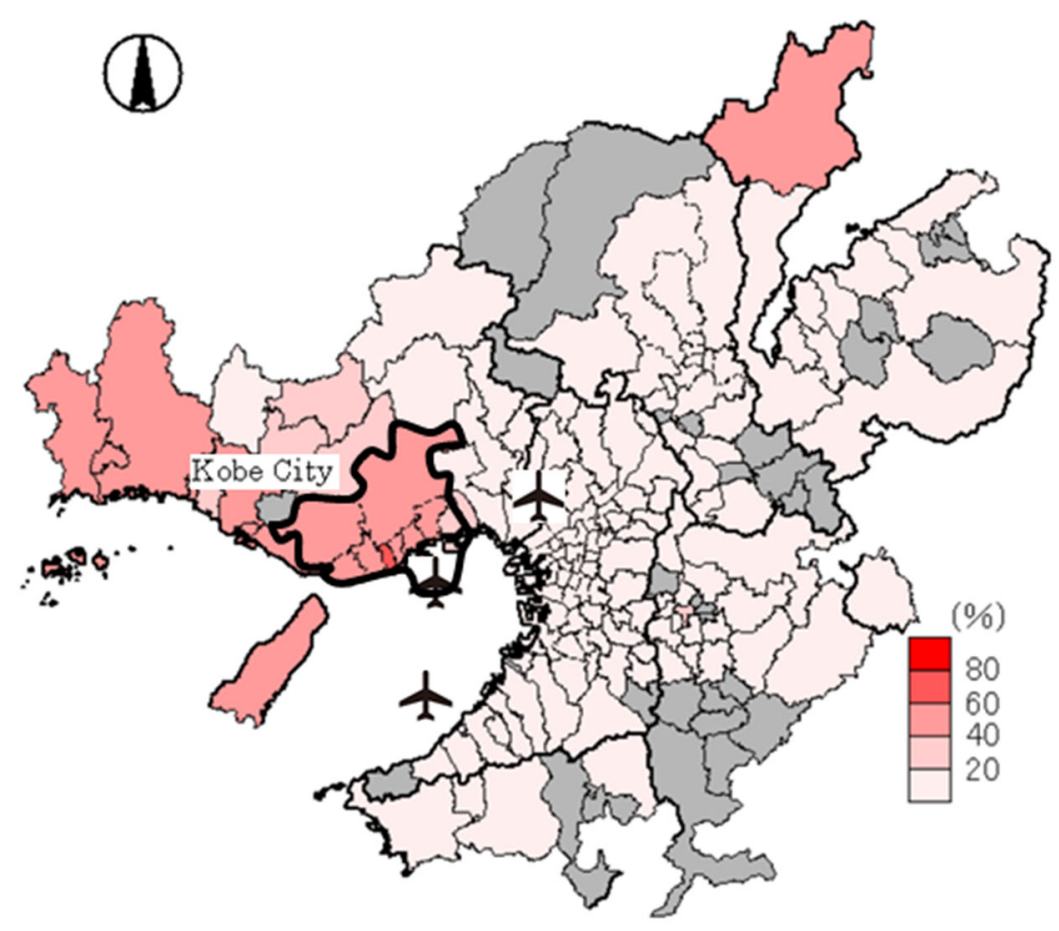

Figure 2. Selection rate of Kobe Airport (UKB) by passengers departing from or arriving at each city

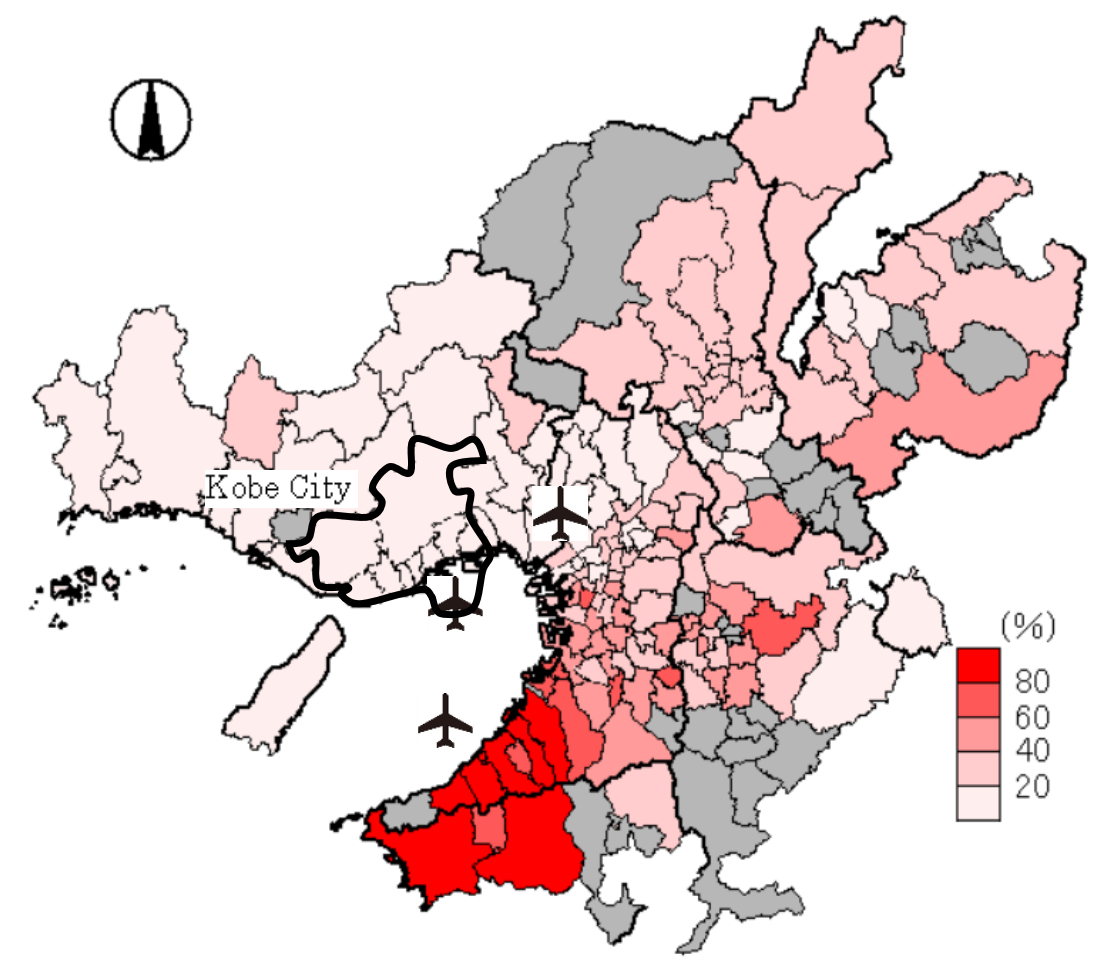

Figure 3. Selection rate of Kansai International Airport (KIX) by passengers departing from or arriving at each city 


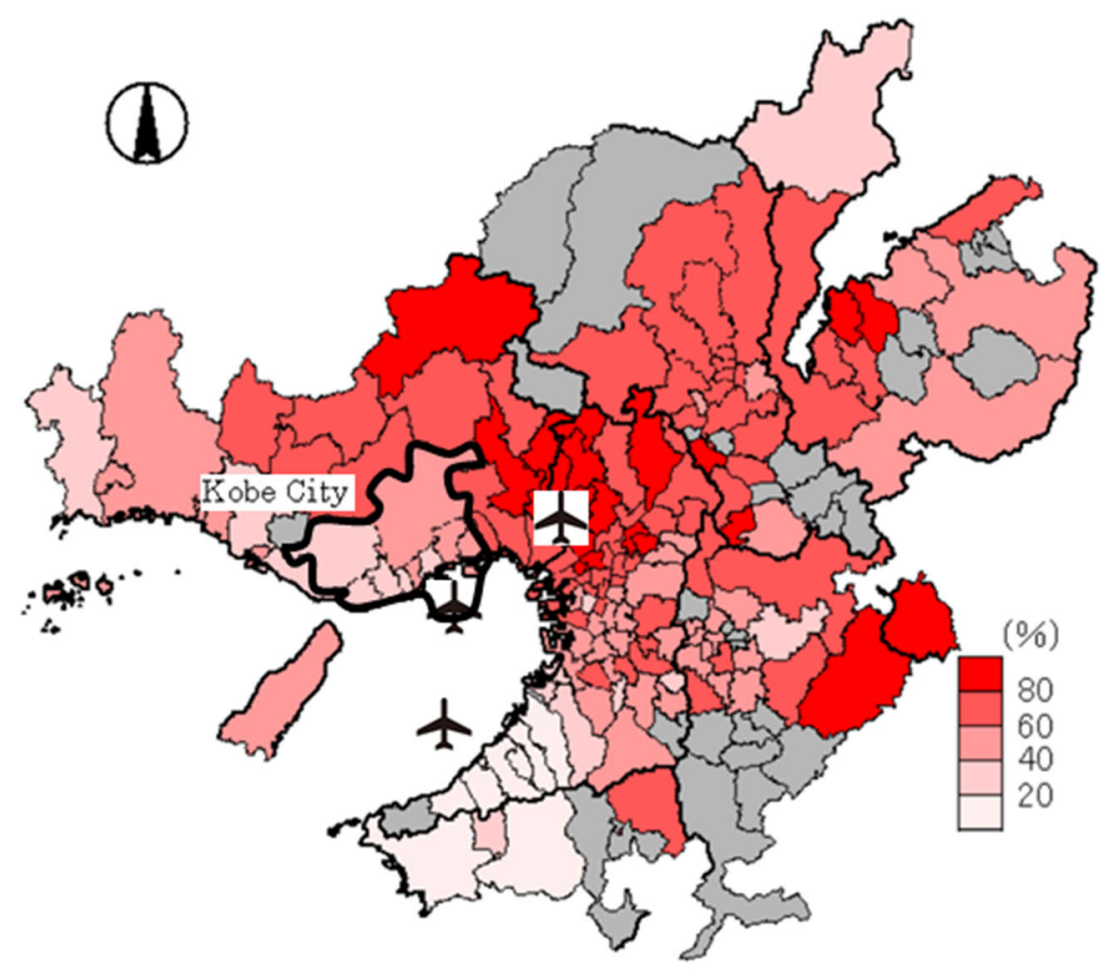

Figure 4. Selection rate of Itami Airport (ITM) by passengers departing from or arriving at each city

\section{EMPIRICAL CONTIBUTION}

\subsection{Modelling Passengers' Behaviour}

In this study, the NL model was used to formulate passengers' airport choice behaviour. The decision tree of passengers is shown in Figure 5. It shows passengers' first level decisions of airline type-that is, full-service carrier (FSC) ${ }^{3}$ or low-cost carrier (LCC) ${ }^{4}$ and the second level decisions of airport from among KIX, TIM and UKB. The alternative sets at the first and second level are denoted as $t \in\{F S C, L C C\}$ and $a \in$ $\{K I X, I T M, U K B\}$.

The explanatory variables are set to explain passengers' decisions at each level. For airline type selection at the first level, it is expected that decision making will differ depending on whether the purpose of the trip is business or leisure. Business passengers generally have a higher time value and require on-time performance, whereas leisure passengers put more value on lower ticket prices because they purchase tickets at their own expense. Thus, a dummy variable $\left(\operatorname{BUSINESS}_{n}\right)$ representing business passengers is used to capture the effects of travel purpose. Here, $n \in\{1,2, \ldots, N\}$ denotes the index

\footnotetext{
3 In this research, FSC refers to JAL and ANA and the airlines that code-share with them (except Jetstar). 4 LCC refers to Peach, Jetstar and Skymark.
} 
of passengers.

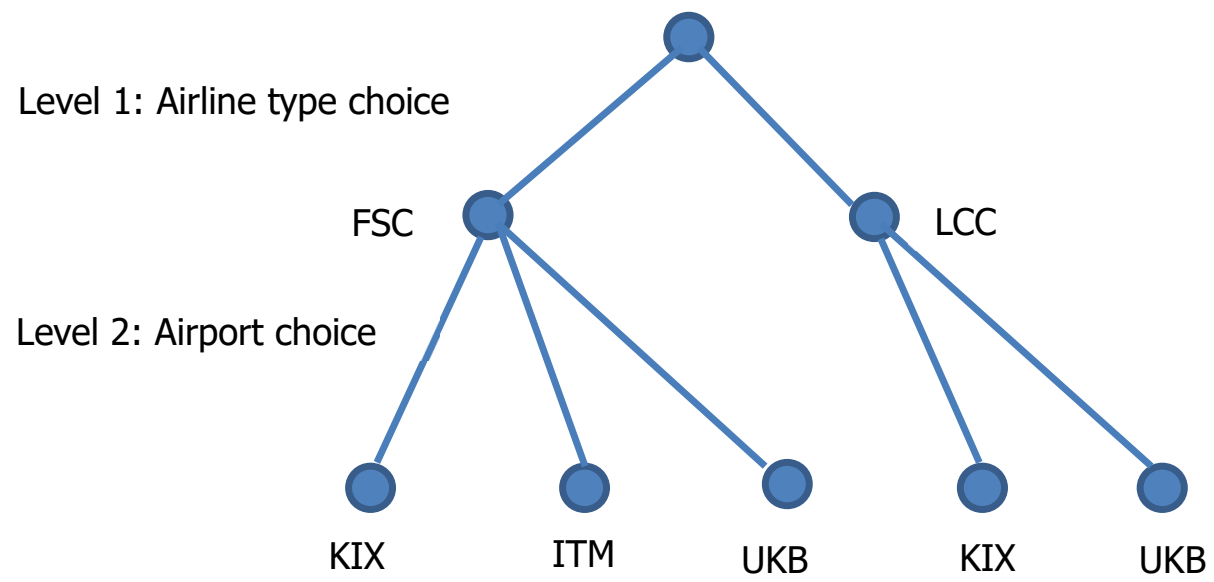

Figure 5. Decision flow of passengers

For the airport choice at the second level, access time ( $\left.A T I M E_{a n}\right)$, access ( $\left.A C O S T_{a n}\right)$ and scheduling cost $\left(S C_{t a n}\right)$ are used as explanatory variables. Access time and access cost are included in the analysis because passengers are expected to take the accessibility to each airport into account in choosing the airport. Scheduling cost is used to represent the convenience of flight schedule. Scheduling cost refers to the cost to adjust a schedule when there is a difference between the desired departure time and the actual departure time. In addition to these, a dummy variable $\left(K O B E_{a n}\right)$ for Kobe citizens was created. The $K O B E_{a n}$ dummy variable, which is the originality of this paper, is set to capture the preference of Kobe citizens for UKB. Note that ticket price is an important factor in decision making (Chang and Sun 2012; Jung and Yoo 2014), but this cannot be included as an explanatory variable due to the nature of its data, as discussed below.

\subsection{Micro Data and Explanatory Variables}

The micro data are taken from the 'Travel Survey for Domestic Air Passengers', conducted by Ministry of Land, Infrastructure, Transportation and Tourism (MLIT) in 2015. The advantage of this survey is that it covers all boarding passengers on all flights on the survey date (21 October 2015), which allows for avoiding sampling bias. The overall survey had 166,791 responses with a response rate of $59.6 \%$. This data are categorised as revealed preference (RP) data because they are a collection of actual passengers' behaviour. The reason to use RP data is that they directly capture reality. However, RP data have a disadvantage in that they do not provide information on alternatives that were not chosen. For this reason, ticket prices could not be included in the analysis of 
this research. In contrast, stated preference (SP) data that are collected by questionnaires or interviews have an advantage in that the decision-making situation for all choices is clear because researchers set hypothetical alternatives, and respondents choose from them. Thus, the researchers can include factors they want to focus on (e.g., de Luca (2012) and Paliska et al. (2016)). However, SP data have a major problem in that all the choices are hypothetical, and there can be a gap between the actual behaviour and the answers provided. Comparing the advantages and disadvantages of both types of data, this research adopted RP data to capture actual behaviours because, in general, passengers decide their choices without recognising attachment to a specific airport.

The analysis targets are passengers whose origin or destination is in GKA and who took a flight on the Sapporo or Naha route. Although all the three airports have routes to/from Sendai, Tokyo, Nagasaki and Kagoshima as well, these routes were excluded from the analysis. This is because passengers firstly make a mode choice between airways or railways on these short haul routes, and thus passengers' decision making does not conform to the airport choice model in this research. According to the Inter-Regional Travel Survey, conducted in 2010 by MLIT, railways occupy $71.6 \%$ of traffic between Osaka and Tokyo, and flights occupy only $18.6 \%$. Approximately half of the passengers to/from Sendai, Nagasaki and Kagoshima took railways. Passengers under 15 years old were also excluded from the data set of this study because they are more likely to just accompany their parents or other adults rather than chose the airport by themselves. Therefore, 3885 individuals remained in the sample for the analysis. The descriptive statistics of the sample are summarised in Table 2.

The explanatory variables are set as the following. In the 'Travel Survey for Domestic Air Passengers', the purpose of the trip was chosen among one of four reasons: business, sightseeing, visiting relatives and friends and other. The $\operatorname{BUSINESS}_{n}$ dummy variable is 1 when the travel purpose is business and the airline type is LCC and 0 otherwise. Two variables, $A T I M E_{a n}$ and $A C O S T_{a n}$, are used to describe airport access. Since the survey asked for the origin or destination at the city level, the central station of the city is assumed as the departing or arriving points of travel. The access time (in minutes) and cost (in thousands of yen) by train from the central station of each city to airport $a$ are used as the values for $A T I M E_{a n}$ and $A C O S T_{a n}$. In calculating $S C_{\text {tan }}$, it is assumed that the scheduling cost is proportional to the inverse of the number of flights. Therefore, 
$S C_{\text {tan }}$ of the airline type $t$ at airport $a$ is calculated as $1 / f_{t a}$. Here, $f_{t a}$ denotes flight frequency. The flight schedule of October 2015, when the survey was conducted, is used for the values of $f_{t a}$. The $K O B E_{a n}$ dummy variable is set to 1 if a passenger is a Kobe citizen and his/her departure airport is UKB. Note that origin/destination cities and residential cities are distinguished in the database because the survey asked for these places separately.

Table 2. Sample data

\begin{tabular}{|c|c|c|c|c|}
\hline \multicolumn{3}{|l|}{ Total samples } & 3885 & \\
\hline \multirow{2}{*}{ Travel purpose } & \multicolumn{2}{|l|}{ Business } & 1024 & $26.4 \%$ \\
\hline & \multicolumn{2}{|l|}{ Leisure } & 2861 & $73.6 \%$ \\
\hline \multirow{5}{*}{ Airline type and airports } & \multicolumn{2}{|l|}{$\mathrm{KIX}$} & 1281 & $33.0 \%$ \\
\hline & \multirow{2}{*}{ ITM } & FSC & 997 & $25.7 \%$ \\
\hline & & LCC & 906 & $23.3 \%$ \\
\hline & \multirow{2}{*}{ UKB } & FSC & 386 & $9.9 \%$ \\
\hline & & LCC & 315 & $8.1 \%$ \\
\hline \multicolumn{3}{|l|}{ Average access time (min.) } & 71 & \\
\hline \multirow{8}{*}{$\begin{array}{l}\text { Passengers living } \\
\text { around airports }\end{array}$} & \multicolumn{2}{|l|}{ Around ITM } & 121 & \\
\hline & \multicolumn{2}{|l|}{ Around KIX } & 49 & \\
\hline & \multirow{6}{*}{ Around UKB } & Kobe & 289 & \\
\hline & & Amagasaki & 88 & \\
\hline & & Nishinomiya & 93 & \\
\hline & & Ashiya & 29 & \\
\hline & & Akashi & 53 & \\
\hline & & Kakogawa & 40 & \\
\hline
\end{tabular}

\section{RESULTS AND DISCUSSION}

In subsection 5.1. the results from the empirical model explained in Section 4 are discussed. Then, subsection 5.2. to 5.4. focus on various factors, such as travel purposes, passengers near ITM and KIK, and passengers around Kobe to analyse Kobe citizens behaviour deeply.

\subsection{Basic Model}

Table 3 shows the results of the analysis using the basic model described in Section 4. Decisions on the airline type choice at the first level differ based on the travel purpose. The coefficient of BUSINESS is negative at the $0.5 \%$ significance level, which indicates that business passengers are more likely to choose FSCs rather than LCCs when compared to non-business passengers. This may reflect the tendency of business travellers who place a high value on on-time performance and business environment on board and at airports. In addition, according to Miliotiet al. (2015), business travellers 
value frequent flyers program in their choice of airline. For these reasons, they prefer FSCs that in general provide high-quality services.

ATIME and ACOST, which affect airport choices at the second level, are negative at the $0.5 \%$ significance level. This indicates that passengers prefer airports with shorter access times and lower access costs. Although $S D$ is not statistically significant at even $10 \%$ significance level, the sign is negative. This implies that frequent flight services attract passengers because they can take a flight that fits their schedule. The reason $S D$ is not statistically significant is that non-business passengers do not avoid airports with low flight frequency, as will be discussed in sub-section 5.2. The signs of the coefficients of the explanatory variables are consistent with intuition. Furthermore, previous papers, such as those by Ong and Tan (2010), Baser and Bhat (2004) and Hess and Polak (2005) also showed similar results. Thus, it can be considered that the model adequately captures passengers' behaviour.

Table 3. Modelling results of the basic model

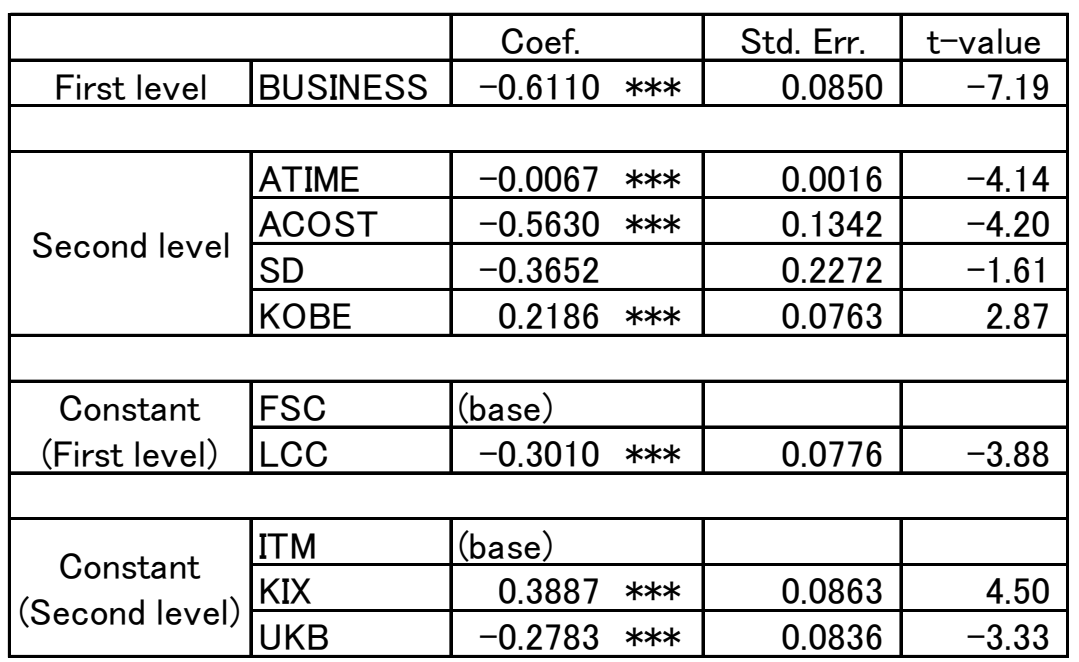

*** Significant at the 0.005level.

** Significant at the 0.01 level.

* Significant at the 0.05 level.

The $K O B E$ dummy variable, which is the focus of this research, is positive at the $0.5 \%$ level of significance. This means that Kobe citizens tend to choose UKB when compared to other passengers, even after controlling for all factors that could influence passengers' decisions. 


\subsection{Results By Travel Purpose}

Next, passengers' decisions were analysed based on their travel purpose to check whether business and non-business travellers have different preferences. Since the data were analysed separately for business and non-business passengers, the BUSINESS dummy variable was excluded from the explanatory variables of the first level. Tables 4 and 5 summarise the results for business and non-business passengers, respectively. For both types of passengers, ATIME and ACOST are negative at the $1 \%$ or $0.5 \%$ level of significance, which is the same as the results of the overall analysis. While $S D$ is negative for business passengers at the $5 \%$ significance level, the sign of $S D$ is not significant for non-business passengers. The background of this result can be considered in that the schedules of business passengers to attend meetings and visit their customers are fixed, whereas non-business passengers have a flexible schedule. Loo (2008) also reported that business passengers place more importance on flight frequency than nonbusiness passengers. The $K O B E$ dummy variable is positive at the $5 \%$ significance level for both type of passengers. Therefore, it was found that Kobe citizens tend to choose UKB regardless of their travel purposes.

Table 4. Modelling results using business passengers' data

\begin{tabular}{|c|c|c|c|c|c|}
\hline & & Coef. & & Std. Err. & $\mathrm{t}$-value \\
\hline \multirow{4}{*}{ Second level } & ATIME & -0.0091 & $* *$ & 0.0036 & -2.51 \\
\hline & ACOST & -0.7904 & $* *$ & 0.2930 & -2.70 \\
\hline & SD & -1.5225 & $*$ & 0.7604 & -2.00 \\
\hline & KOBE & 0.4594 & * & 0.2130 & 2.16 \\
\hline \multirow{2}{*}{$\begin{array}{l}\text { Constant } \\
\text { (First level) }\end{array}$} & FSC & (base) & & & \\
\hline & LCC & -0.7203 & $* * *$ & 0.1669 & -4.26 \\
\hline \multirow{3}{*}{$\begin{array}{c}\text { Constant } \\
\text { (Second level) }\end{array}$} & ITM & (base) & & & \\
\hline & $\mathrm{KIX}$ & 0.4267 & $* * *$ & 0.1523 & 2.80 \\
\hline & UKB & -0.0121 & & 0.1612 & -0.07 \\
\hline
\end{tabular}

$* * *$ Significant at the 0.005 level.

** Significant at the 0.01 level.

* Significant at the 0.05 level.

The following two questions still need to be answered before the results about the regionality of Kobe citizens' behaviours are definitively concluded.

Q1: Do citizens of airport cities, not just Kobe citizens, generally tend to use the airport in their city?

The research question is whether the citizens prefer 'city-owned' airports such as UKB. 
Thus, it is necessary to examine whether there is any difference between local public airports and other national airports.

Q2: Do people living in the neighbouring cities of Kobe also tend to use UKB?

Table 5. Modelling results using non-business passengers' data

\begin{tabular}{|c|c|c|c|c|c|}
\hline & & Coef. & & Std. Err. & $\mathrm{t}$-value \\
\hline \multirow[t]{4}{*}{ Second level } & ATIME & -0.0059 & $* * *$ & 0.0018 & -3.22 \\
\hline & ACOST & -0.4979 & $* * *$ & 0.1525 & -3.26 \\
\hline & SD & 0.1350 & & 0.2263 & 0.60 \\
\hline & KOBE & 0.1648 & $*$ & 0.0784 & 2.10 \\
\hline \multirow[t]{2}{*}{ Constant } & FSC & \multicolumn{2}{|l|}{ (base) } & & \\
\hline & LCC & -0.3620 & $* * *$ & 0.0828 & -4.37 \\
\hline \multirow[t]{3}{*}{ Constant } & ITM & (base) & & & \\
\hline & KIX & 0.3703 & $* * *$ & 0.1068 & 3.47 \\
\hline & UKB & -0.3839 & $* * *$ & 0.1223 & -3.14 \\
\hline
\end{tabular}

*** Significant at the 0.005 level.

** Significant at the 0.01 level.

* Significant at the 0.05 level.

It is worth clarifying whether the regionality of the preference to UKB is specific to Kobe citizens or is common in people living near Kobe. To answer these questions, additional analyses were conducted with new regional dummy variables for the passengers' place of residence.

\subsection{Decisions Of Passengers Near Other Airports}

To clarify differences in behaviour between Kobe citizens and passengers living near other airports, two regional dummy variables, AKIX and AITM, were added to the basic model. AKIX is the dummy variable for passengers living near KIX. 'Near KIX' is defined as Izumisano, Sennan and Tajiri, where KIX is located. This variable takes 1 for passengers who live in these cities and choose KIX and 0 otherwise. Similarly, AITM is set for citizens of Toyonaka and Itami, where ITM is located. The results of the model with the additional dummy variables are shown in Table 6.

The results for the BUSINESS, ATIME, ACOST, SD and KOBE variables are largely similar to those in the basic model. The coefficient of AITM is positive at the $5 \%$ significance level, which indicates that passengers living near ITM also tend to use their local airport. ITM had been scheduled to be closed down after the opening of the new 
airport, KIX. However, ITM remained open due to a campaign by the local government to continue its operation. This history may influence the preference of the citizens close to the airport.

Table 6. Modelling results with AITM and AKIX dummy variables

\begin{tabular}{|c|c|c|c|c|c|}
\hline & & Coef. & & Std. Err. & $\mathrm{t}$-value \\
\hline First level & BUSINESS & -0.6114 & $* * *$ & 0.0850 & -7.19 \\
\hline & ATIME & -0.0061 & $* * *$ & 0.0015 & -4.04 \\
\hline & ACOST & -0.5788 & $* * *$ & 0.1358 & -4.26 \\
\hline Conondlouel & SD & -0.3616 & & 0.2206 & -1.64 \\
\hline secona revel & AITM & 0.2404 & * & 0.1131 & 2.13 \\
\hline & AKIX & -0.6138 & ** & 0.2225 & -2.76 \\
\hline & KOBE & 0.2054 & $* * *$ & 0.0727 & 2.82 \\
\hline Constant & FSC & (base) & & & \\
\hline (First level) & LCC & -0.3096 & $* * *$ & 0.0756 & -4.10 \\
\hline & ITM & (base) & & & \\
\hline constani & KIX & 0.3959 & $* * *$ & 0.0868 & 4.56 \\
\hline & UKB & -0.2554 & $* * *$ & 0.0790 & -3.23 \\
\hline
\end{tabular}

*** Significant at the 0.005level.

** Significant at the 0.01 level.

* Significant at the 0.05 level.

On the other hand, $A K I X$ is negative at the $1 \%$ level of significance. This indicates that passengers living near KIX are rather reluctant to use the airport. In summary, the answer to Q1 is that in general, not all passengers have a preference for their local airports. Further investigation is needed to clarify this point regarding what factors shape preferences for local airports.

\subsection{Decisions Of Passengers Around Kobe}

The next analysis was on the decision making of the citizens of the five neighbouring cities of Kobe. The location of these cities is depicted in Figure 6. The curves in the figure represent the trunk railway lines. AMAGASAKI, NISHINOMIYA, ASHIYA, AKASHI and KAKOGAWA were introduced as new dummy variables. Each variable takes 1 when a passenger is the resident of each city and the choice of airport is UKB and 0 otherwise. The results of the model with these dummy variables are shown in Table 7. 


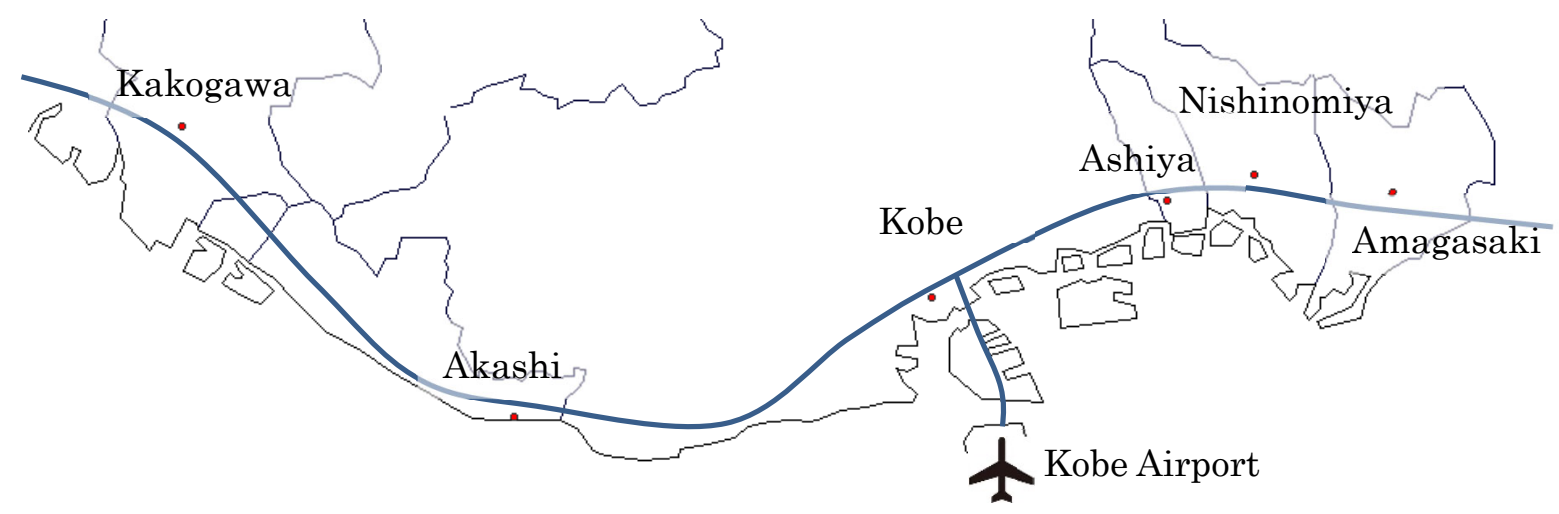

Figure 6. Map around Kobe

Table 7. Modelling results with dummy variables for cities near Kobe

\begin{tabular}{|c|c|c|c|c|c|}
\hline & \multicolumn{2}{|l|}{ Coef. } & Std. Err. & $t$-value \\
\hline First level & BUSINESS & -0.6098 & *** & 0.0850 & -7.17 \\
\hline \multirow{9}{*}{ Second level } & ATIME & -0.0068 & **** & 00016 & -415 \\
\hline & ACOST & -0.5644 & $* * *$ & 0.1363 & -4.14 \\
\hline & SD & -0.3571 & & 0.2436 & -1.47 \\
\hline & AMAGASAKI & 0.0340 & & 0.1040 & 0.33 \\
\hline & NISHINOMIYA & 0.2470 & * & 0.1023 & 2.41 \\
\hline & ASHIYA & 0.3926 & $*$ & 0.1739 & 2.26 \\
\hline & KOBE & 0.3195 & $* * *$ & 0.0949 & 3.37 \\
\hline & AKASHI & 0.5798 & $* * *$ & 0.1986 & 2.92 \\
\hline & KAKOGAWA & 0.1459 & & 0.1419 & 1.03 \\
\hline \multirow{2}{*}{$\begin{array}{l}\text { Constant } \\
\text { (First level) }\end{array}$} & FSC & (base) & & & \\
\hline & LCC & -0.2882 & $* * *$ & 0.0786 & -3.67 \\
\hline \multirow{3}{*}{$\begin{array}{c}\text { Constant } \\
\text { (Second level) }\end{array}$} & ITM & (base) & & & \\
\hline & KIX & 0.3821 & $* * *$ & 0.0849 & 4.50 \\
\hline & UKB & -0.3594 & $* * *$ & 0.0976 & -3.68 \\
\hline
\end{tabular}

*** Significant at the 0.005level.

** Significant at the 0.01 level.

* Significant at the 0.05 level.

In this model, the coefficients for BUSINESS, ATIME, ACOST, SD and KOBE are almost the same as those in the basic model, respectively. The dummy variables for Nishinomiya, Ashiya and Akashi, which are very close to Kobe, are significantly positive, while those for Amagasaki and Kakogawa, which are relatively further away from Kobe, are not statistically significant. This result means that the preference for UKB is limited to passengers living in places very close to Kobe.

In summary, the answer to Q2 (Do people living in the neighbouring cities of Kobe also 
tend to use UKB?) is yes. The reason citizens in the three cities close to Kobe have similar preferences to those of Kobe citizens may be that these cities have a strong connection with Kobe economically and socially. This hypothesis can be examined based on commuting rates to Kobe and the immigration rate from Kobe. Table 8, which is based on the National Census in 2015, summarises the population of the five cities, the number of people commuting to Kobe and the number of people moving in from Kobe.

Table 8. Commuting rates to Kobe and move-in rates from Kobe.

\begin{tabular}{|l|r|r|r|r|r|r|}
\hline & Population & \multicolumn{1}{|c|}{$\begin{array}{c}\text { Workers } \\
\text { and } \\
\text { students }\end{array}$} & \multicolumn{2}{|c|}{$\begin{array}{c}\text { Commuters to } \\
\text { Kobe city }\end{array}$} & \multicolumn{2}{|c|}{$\begin{array}{c}\text { Immigrants from } \\
\text { Kobe city between } \\
2010 \text { and } 2015\end{array}$} \\
\hline Amagasaki & 452,563 & 211,334 & 12,013 & $5.7 \%$ & 3,475 & $0.8 \%$ \\
\hline Nishinomiya & 487,580 & 231,862 & 27,419 & $11.8 \%$ & 7,467 & $1.5 \%$ \\
\hline Ashiya & 95,350 & 44,045 & 9,863 & $22.4 \%$ & 2,975 & $3.1 \%$ \\
\hline Akashi & 293,409 & 142,234 & 40,972 & $28.8 \%$ & 9,064 & $3.1 \%$ \\
\hline Kakogawa & 267,435 & 133,674 & 16,398 & $12.3 \%$ & 2,605 & $1.0 \%$ \\
\hline
\end{tabular}

Firstly, the move-in rates of the three cities with significantly positive regional dummy variables are higher than those of other cities. More than $3 \%$ of the population of Ashiya and Akashi moved in from Kobe in the 5 years between 2010-2015. Including people who moved in before that period, a larger proportion of the population came from Kobe. Thus, it is not surprising that these people have similar preferences to those of Kobe citizens.

Second, commuting rates to Kobe from Nishinomiya, Ashiya and Akashi tend to be higher than those from other cities (Kakogawa's commuting rate is slightly higher than Nishinomiya's). Commuting rates from Akashi and Ashiya to Kobe are over 20\%, so these cities have strong social and economic connections to Kobe. While passengers in areas strongly connected to Kobe prefer UKB, the decisions of passengers in areas with relatively weaker connections to Kobe are not statistically different from the average preferences of all passengers. People who commute to school and work in Kobe may have opportunities to visit UKB for school events or to take flights from UKB for business trips. Thus, it is possible that these social and economic connections make their airport choices similarly to Kobe citizens.

\section{DOES ATTACHMENT TO A SPECIFIC AIRPORT AFFECT AIRPORT CHOICES?}

Section 5 has indirectly presented the attachment to and preference for city-owned airports based on actual passengers' decisions. However, since the RP data did not 
include a variable related to attachment, it was not possible to explicitly describe direct links between passengers' attachment and choice. Therefore, an additional survey of Kobe citizens was conducted to determine whether their attachment to UKB is linked to their airport choice.

The survey was conducted on the Internet using the services of Macromill Inc. In this survey, respondents are sent e-mail with URL to the questionnaire page. For random sampling purpose, the company select respondents at random from the Kobe citizen monitors registered with Macromill. Note that the respondents may be biased towards those interested in airports and travel because the monitors could decide whether to respond the survey after seeing its title in the questionnaire page. There were 206 respondents in total, including 103 men and women respectively, each in their 30s to 50s. The survey asked respondents to select a flight to take out of six flights departing from the three airports. The combination of airlines, airports and fares for each flight reflects actual market conditions. See Table 9 for the detail of the flights. The respondents were also asked if they feel any attachment to UKB and why they chose that flight.

Table 9. Flight choice set

\begin{tabular}{|r|r|l|l|l|}
\hline Departure & Arrival & Airport & Airline & Fare \\
\hline $8: 00$ & $9: 55$ & KIX & JAL & 14,300 \\
\hline $8: 00$ & $9: 50$ & ITM & ANA & 14,730 \\
\hline $8: 10$ & $9: 55$ & UKB & Skymark & 10,770 \\
\hline $8: 20$ & $10: 05$ & ITM & JAL & 14,730 \\
\hline $8: 20$ & $10: 15$ & KIX & Peach & 10,190 \\
\hline $8: 25$ & $10: 20$ & UKB & ANA & 13,870 \\
\hline
\end{tabular}

The results of the survey are summarised in Figure 7. The number of respondents who feel attachment to UKB was 98, of which, 89 chose to fly from UKB. Conversely, 108 respondents were not attached to the airport, and yet 99 of them chose to depart from UKB. The selection rates for UKB are $90.8 \%$ for the with-attachment group and $91.7 \%$ for the without-attachment group, and there is no large difference between the two groups in terms of airport choice. However, these two groups answered differently to a question about the reason for choosing the flight. The results showed that $19.1 \%$ of respondents with attachment answered that they chose a flight from UKB because they 
love the airport'. Conversely, no respondent without attachment attributed their flight choice to their love of the airport. This result indicates that the psychological factor of attachment can arouse a preference for a specific airport and can be a reason for choosing the airport to some extent. So, it might be a possible idea for policy makers of airport cities to hold events such as runway walks and field trips for their citizens to enhance attachment to the airport and increase its passengers. Kobe and UKB invite children for 1-day airport tours, and the participants feel attachment to the airport as a result.

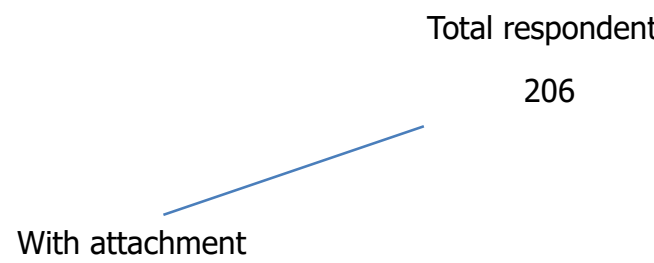

98

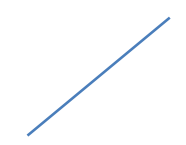

Flight from UKB

$89(90.8 \%)$

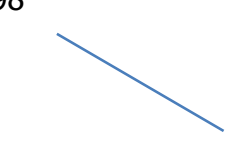

Flight from ITM or KIX

$9(9.2 \%)$

$17(19.1 \%)$ of them choose UKB

because they love it

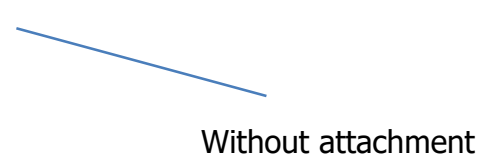

108

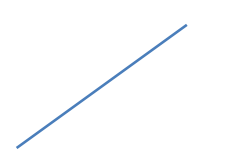

Flight from UKB

$99(91.7 \%)$

None of them choose UKB

because they love it

Figure 7. Results of the questionnaire survey

\section{CONCLUSIONS}

In this paper, an empirical analysis was conducted using micro data to examine whether passengers in a city with a local public airport tend to choose that airport. The analysis took Greater Kansai Area with multiple airports and Kobe as an example. The basic model showed that Kobe citizens prefer the local public airport when compared to passengers in other regions. The additional analysis on airport choice for non-Kobe citizens provided two results. Firstly, residents in other airport cities do not necessarily choose their local airports. Secondly, passengers living in cities with strong economic and social connections with Kobe also tend to use Kobe Airport (UKB). This means that passengers in these cities have a similar preference as Kobe citizens. Finally, the questionnaire survey revealed that a certain portion of people who are attached to UKB choose flights from UKB because they like the airport itself. This result suggests that attachment to a specific airport can be a reason for using it. 
Although this research obtained meaningful results, future tasks are still left to be researched. The revealed preferences data used in the analysis have the disadvantage that they include only observable variables. For this reason, it is not possible to directly confirm whether passengers' decisions are affected by their attachment to a specific local airport. Therefore, this study indirectly demonstrates the existence of a relationship between attachment and airport choice based on the additional questionnaire survey.

To clarify whether attachment to an airport influences airport choice, it may be useful to conduct a questionnaire survey of passengers at airports. This makes it possible to collect data including attachment from passengers waiting to board who have finished airport choice and expressed their actual preferences. This eliminates the disadvantages of questionnaire survey in that questions must be hypothetical. Thus, it can be considered that this method helps researchers to directly analyse the relationship between attachment and airport choice.

\section{REFERENCES}

- Basar, G. and Bhat, C. (2004) 'A Parameterized Consideration Set Model for Airport Choice: An Application to the San Francisco Bay Area', Transportation Research Part B, 38, 889-904.

- Basso, L., Clements, M. and Ross, T. (2009) 'Moral Hazard and Customer Loyalty Programs', American Economic Journal: Microeconomics, 1, 101-123.

- Bezerra, G. and Gomes, C. (2019) 'Determinants of Passenger Loyalty in Multi-Airport Regions: Implications for Tourism Destination', Tourism Management Perspectives, 1 , 145-158.

- Castro, R. and Lohmann, G. (2014) 'Airport Branding: Content Analysis of Vision Statements', Research in Transportation Business \& Management, 10, 4-14.

- Chang, L. and Sun, P. (2012) 'Stated-Choice Analysis of Willingness to Pay for LowCost Carrier Services', Journal of Air Transport Management, 20, 15-17.

- de Boer, E. and Gudmundsson, S. (2012) '30 Years of Frequent Flyer Programs', Journal of Air Transport Management, 24, 18-24.

- de Luca (2012) 'Modelling airport choice behaviour for direct flights, connecting flights anddifferent travel plans', Journal of Transport Geography, 22, 148-163.

- Halpern, N. and Graham, A. (2013) 'Airport Marketing', Routledge

- Harvey, G. (1987) 'Airport Choice in a Multiple Airport Region', Transportation Research Part A, 21, 439-449. 
- Hess, S., Adler, T. and Polak, J.W. (2007) 'Modelling airport and airline choice behaviour with the use of stated preference survey data' Transportation Research Part $E, 43,221-233$

- Hess, S. and Polak, J. (2005) 'Mixed Logit Modelling of Airport Choice in Multi-Airport Regions', Journal of Air Transport Management, 11, 59-68.

- Innes, J. D. and Doucet, D. H. (1990) 'Effects of Access Distance and Level of Service on Airport Choice', Journal of Transportation Engineering, 116, 507-516.

- Jones, M.A., Mothersbaugh, D.L. and Beatty, S.E. (2002) 'Why Customers Stay: Measuring the Underlying Dimensions of Services Switching Costs and Managing their Differential Strategic Outcomes', Journal of Business Research, 55, 441-450.

- Jung, S. and Yoo, K. (2016) 'A Study on Passengers' Airport Choice Behavior Using Hybrid Choice Model: A Case Study of Seoul Metropolitan Area, South Korea', Journal of Air Transport Management, 57, 70-79.

- Lian, J.I. and Ronnevik, J. (2011) 'Airport Competition-Regional Airports Losing Ground to Main Airports', Journal of Transport Geography, 19, 85-92.

- Loo, B. (2008) 'Passengers' Airport Choice Within Multi-Airport Regions (MARs): Some Insights from a Stated Preference Survey at Hong Kong International Airport', Journal of Transport Geography, 16, 117-125.

- Marcucci, E. and Gatta, V. (2011) 'Regional airport choice: Consumer behaviour and policy implications', Journal of Transport Geography, 19, 70-84.

- McEntee, J. (2010) 'Contemporary and Traditional Localism: A Conceptualisation of Rural Local Food', The International Journal of Justice and Sustainability, 15, 785803.

- Milioti, C., Karlaftis, M. and Akkogiounoglou, E. (2015) 'Traveler Perceptions and Airline Choice: A Multivariate Probit Approach', Journal of Air Transport Management, 49, 46-52.

- Morimoto, Y. (2019) 'Demand Leakage from a Local Small Airport to a Regional Main Airport', International Journal of Humanities, Arts and Social Sciences, 5, 36-42.

- Nesset, E. and Helgesen, O. (2014) 'Effects of Switching Costs on Customer Attitude Loyalty to an Airport in a Multi-Airport Region', Transportation Research Part A, 67, 240-253.

- Ong, W. and Tan, A. (2010) 'A Note on the Determinants of Airline Choice: The Case of Air Asia and Malaysia Airlines', Journal of Air Transport Management, 16, 209-212.

- Pels, E., Nijkamp, P. and Rietveld, P. (2000) 'Airport and Airline Competition for Passengers Departing from a Large Metropolitan Area', Journal of Urban Economics, 
$48,29-45$.

- Paliska, D., Drobne, S., Borruso, G., Gardina, M. and Fabjan, D. (2016) 'Passengers' airport choice and airports' catchment area analysis incross-border Upper Adriatic multi-airport region', Journal of Air Transport Management, 57, 143-154.

- Saffu, K., Walker, K. and Mazurek, M. (2010) 'The Role of Consumer Ethnocentrism in a Buy National Campaign in a Transitioning Country: Some Evidence from Slovakia', International Journal of Emerging Markets, 5, 203-226.

- Seasholes, M. and Zhu, N. (2013) 'Investing in What You Know: The Case of Individual Investors and Local Stocks', Journal Of Investment Management, 11, 2030.

- Windle, R. and Dresner, M. (1995) 'Airport Choice in Multiple-Airport Regions', Journal of Transportation Engineering, 124, 332-337.

- Zhou, H., Xia, J., Norman, R., Hughes, B., Nikolova, G., Kelobonye, K., Du, K. and Falkmer, T. (2019) 'Do Air Passengers Behave Differently to Other Regional Travellers?: A Travel Mode Choice Model Investigation', Journal of Air Transport Management, 79, 101682.

\section{AUTHORS' BIO}

Dr Yu Morimoto (corresponding author) is a transportation economist who obtained $\mathrm{PhD}$ in Economics from Kyoto University in 2016. The title of his doctoral thesis is "Economic Analysis of Policies on Air-transportation Market". He has been teaching "Introduction to Microeconomics", "Introduction to Japanese economy" and "Industrial organisation" in Konan University since 2016. Email: y mrmt@konan-u.ac.jp

Dr Takeshi Koide is a mathematical engineer who obtained $\mathrm{PhD}$ in Engineering from Osaka University in 2000. The title of his doctoral thesis is "A Study on Reliability Estimation and Design Problem for Network Systems". He has been teaching "Probability and Statistics", "Operations Research" and "Optimization" in Konan University since 2009. Email: koide@konan-u.ac.jp

Yuko Sugiura is a Shakespearean scholar who obtained MA in Shakespeare Studies from University of Birmingham in 2001 and PhD in English Literature from Fukuoka Women's University in 2008. The title of her doctoral thesis is "Illusions in Shakespeare's Plays". She has been teaching "History of British Literature", "Reading Literature in 
English" and "Introduction to British and American Literature and Culture" in Konan University since 2016. In this paper, she worked mainly in researching the history of Kobe Airport and checking English sentences. Email: yukosugi@konan-u.ac.jp 